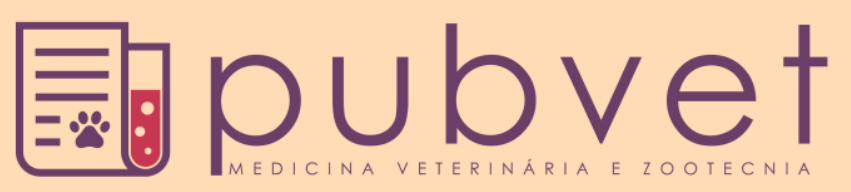

HTTP://DX.DOI.ORG/10.22256/PUBVET.V11N10.970-980

\title{
Bioética e bem-estar na gestação e no parto da fêmea bovina
}

\author{
Jackson Barros do Amaral ${ }^{1 *}$, Guilherme Trevisan² \\ ${ }^{I}$ Médico Veterinário, Pesquisador Científico do Centro de Análise e Pesquisa Tecnológica dos Agronegócios de Bovinos de Leite, Instituto de \\ Zootecnia, Agência Paulista de Tecnologia dos Agronegócios, Secretaria de Agricultura e Abastecimento do Estado de São Paulo, Caixa \\ Postal 60, CEP 13460-000, Nova Odessa, SP. \\ ${ }^{2}$ Médico Veterinário, Mestrando da Faculdade de Medicina Veterinária e Zootecnia da Universidade Estadual Paulista "Júlio de Mesquita \\ Filho”- Distrito de Rubião Jr., s/n - Botucatu/SP CEP 18618-970, e-mail guilherme_med.vet@live.com \\ *Autor para correspondência, E-mail: jackson@iz.sp.gov.br
}

RESUMO. Os procedimentos para inovações na exploração animal têm evoluído ao longo dos anos no mundo inteiro. Alguns deles vêm comprometendo os limites da ética, notadamente no uso dos animais de produção. Neste contexto, o cenário de controle social acerca do uso dos animais de produção começou a ser cada vez mais evidente. A bioética e a ciência do bem-estar vêm contribuindo na análise de todo processo de controle sobre a criação dos animais, abrindo caminho para a ideia de dignidade entre todas as formas de vida. Desta forma, merece ser digno de nota o crescimento da bovinocultura nacional. Cada dia que passa a demanda da cadeia de produção de carne e leite faz com que a exploração de bovinos seja mais intensa. Não há dúvidas que essa intensidade tenha proporcionado ganhos econômicos e sociais importantes, mas também tenha resultado em problemas quanto ao bem-estar animal e aos limites da ética. Acreditamos na possibilidade de desenvolvermos novas técnicas de criação que garantam bons índices de produtividade e alta qualidade dos produtos, sem comprometer o bem-estar dos animais. No sistema de criação o manejo da gestante e a assistência ao parto da fêmea bovina devem ser diferenciados, pelo fato da mesma estar incluída numa categoria especial. Fundamentado neste contexto, este artigo tem o propósito de abordar as relações estabelecidas entre o homem e os bovinos, objetivando discutir o manejo da gestante e à assistência ao parto, da forma mais humanitária possível, considerando os aspectos éticos e de bem-estar.

Palavras chave: ética, distocia, negligência, obstetrícia, prenhez, vaca

\section{Bioethics and welfare on pregnancy and parturition of bovine females}

ABSTRACT. The procedure for innovations in animal exploitation has involved over the long term all over the world. Some of them have compromised the limits of ethics, notably on the use of production animals. In this context, the scenario of social control over the use of production animals began to be increasingly evidence. Bioethics and the science of well being have been contributing to the analysis of the whole process of control over animal raising, opening the way for the idea of dignity among all forms of life. In this way, it is worth considering the growth of national cattle production. Each passing day the demand of meat and milk production chain makes cattle exploitation even more intense. There is no doubt that this intensity has important economic and social gains, but it also has an effect on animal welfare and the limits of ethics. We believe in the possibility of developing new animal raising techniques that guarantee good productivity and high product quality without compromising animal welfare. In the raising system the pregnancy management and the assistance to labor to the bovine female should be differentiated, to the fact that this animal is included in a special category. Based on this context, this article aims to address the relationships established between man and cattle, aiming to discuss pregnancy 
management and labor assistance, in the most human form possible, considering the ethical and welfare aspects.

Key words: ethics, dystocia, neglect, obstetrics, pregnancy, cow

\section{Bioética y bienestar en la gestación y en el parto de la hembra bovina}

RESUMEN. Los procedimientos para las innovaciones en la producción animal han evolucionado a lo largo de los años en todo el mundo. Algunos de ellos vienen comprometiendo los límites de la ética, especialmente en el uso de animales de producción. En este contexto, el escenario de control social sobre el uso de los animales de producción comenzó a ser cada vez más evidente. La bioética y la ciencia del bienestar vienen contribuyendo en el análisis de todo proceso de control sobre la cría de animales, abriendo camino a la idea de dignidad entre todas las formas de vida. De esta forma, merece ser digno de mención el crecimiento de la ganadería nacional. Cada día que pasa, la demanda de la cadena de producción de carne y leche hace que la producción de bovinos sea más intensa. No hay duda de que esa intensidad haya proporcionado ganancias económicas y sociales importantes, pero también ha resultado en problemas en cuanto al bienestar animal y a los límites de la ética se refiere. Creemos en la posibilidad de desarrollar nuevas técnicas de cría que garanticen buenos índices de productividad y alta calidad de los productos, sin comprometer el bienestar de los animales. En el sistema de cría, el manejo de la gestante y la asistencia al parto de la hembra bovina deben ser diferenciados, por el hecho de la misma estar incluida en una categoría especial. Fundamentado en este contexto, este artículo tiene el propósito de abordar las relaciones establecidas entre el hombre y los bovinos, con el objetivo de discutir el manejo de la gestante y la asistencia al parto, de la forma más humanitaria posible, considerando los aspectos éticos y de bienestar.

Palabras clave: ética, distocia, negligencia, obstetricia, preñez, vaca

\section{Introdução}

Nas últimas três décadas os países desenvolvidos têm tido uma preocupação significativa quanto ao tratamento dos animais. No Brasil este comportamento começa a despertar os interesses sociais a este respeito. Cada vez mais prevalece à preocupação com o bem-estar dos animais e a rejeição à negligência, à crueldade $\mathrm{e}$ aos maus-tratos. Talvez, os fatos mais evidentes sejam o empenho na elaboração de várias leis e as políticas públicas que têm sido adotadas.

A qualidade dos métodos de criação e do manejo dos animais vem ganhando ênfase no que diz respeito à produção da "carne ética", ou seja, aquela obtida de forma mais humanitária possível (Hellebrekers, 2002). Este autor menciona que é necessária a utilização de métodos de criação onde os animais não sofram maus-tratos, dor, estresse ou qualquer injúria desnecessária durante a vida produtiva. Enfatiza também que o tratamento dos animais de produção na agricultura industrializada tornou-se uma prioridade na Europa, sendo que a Suécia aprovou uma legislação em 1988, proibindo a agricultura de confinamento e criando o que o "New York Times" chamou de "Bill of Rights" (Declaração de Direitos) para os animais de fazenda. Regras semelhantes foram promulgadas na Inglaterra, e hoje o bem-estar de animais de produção é uma prioridade para a Comunidade Europeia. A gestação é um estado especial do organismo da fêmea, no qual ocorrem modificações fisiológicas e comportamentais importantes. Sendo assim, vacas e novilhas gestantes constituem uma categoria de destaque no sistema de produção, são as promotoras da multiplicação e produção de leite; assim, necessitam de tratamentos diferenciados. No entanto, sabe-se que, muitas vezes, as fêmeas gestantes são tratadas com negligência. Fundamentado neste contexto, este artigo tem o propósito de abordar a importância dos principais aspectos relacionados à bioética e ao bem-estar das fêmeas bovinas, durante a gestação e no decorrer dos períodos do pré-parto, do parto e do pós-parto.

\section{Bem-estar animal}

A compreensão do bem-estar animal não é simples, exige conhecimento sobre a espécie em questão e demanda uma abordagem multidisciplinar, envolvendo conceitos de várias áreas de conhecimento. Diversas pesquisas têm 
sido conduzidas com objetivo de avaliar a importância do bem-estar animal na opinião pública e tem demonstrado que o tema desperta preocupação (Bennett, 1998, Glass et al., 2005). Em várias situações a intensificação do bem-estar animal reflete na saúde animal e coincide com as prioridades dos produtores (Molento, 2005). No entanto, esta autora enfatiza que nem sempre há coincidência entre o mínimo de custo possível e um determinado padrão de bem-estar.

No meio científico surgiram as Comissões de Ética no Uso de Animais (CEUAs) as quais são responsáveis pelo controle e valorização do bemestar animal. Todavia, ainda falta muito para atingir os padrões dos países desenvolvidos, nos quais já existem sociedades protetoras de animais bem estruturadas e leis de proteção animal bem definidas. O bem-estar animal é um tema bastante polêmico, quando se discute a criação de animais para o consumo (Paranhos da Costa, 2004). Esse autor menciona que fora do meio acadêmico esse tema é geralmente tratado do ponto de vista ético, com grupos que atuam em defesa dos animais, bem como seus direitos, pressionando para definição de normas legais que limitem a ação do homem no trato com os animais. Ainda, enfatiza que esses grupos emanam forças que vem crescendo de maneira acentuada, de forma que grande parte da legislação da União Europeia foi elaborada sob essas influências.

Um grande marco foi à definição das "cinco liberdades" para avaliação do bem-estar animal, que são aceitas Internacionalmente. Estas liberdades foram definidas na Inglaterra, em 1993, pelo Comitê de Bem-estar dos Animais de Produção (Farm Animal Welfare Commitee) (FAWC, 2009) sendo elas a liberdade nutricional, onde os animais devem estar livres de fome, sede e desnutrição; liberdade sanitária deve estar livre de dor, injúrias e doenças; liberdade comportamental deve ter liberdade suficiente para expressar o comportamento natural da sua espécie; liberdade psicológica deve estar livre de sensações de medo e de ansiedade e, finalmente a liberdade ambiental, na qual os animais devem ter liberdade suficiente de movimento, em instalações adequadas à sua espécie.

\section{Diagnóstico da gestação}

O diagnóstico de gestação permite determinar a existência e o período de gestação (Goçalves et al., 2008, Pereira et al., 2010). Estes autores mencionam que em bovinos, a palpação retal foi, e vem sendo utilizada como técnica para esse diagnóstico desde $\mathrm{o}$ início do século $\mathrm{XX}$. Esclarecem também que na década de 80 o emprego da técnica de ultrassonografia possibilitou o diagnóstico de gestação em fases mais precoces. Como recurso diagnóstico especial, a ultrassonografia destaca-se, principalmente, devido à praticidade e execução e a característica não invasiva do método (Pierson, 1989). Sendo, ainda, importantes para diagnosticar perdas embrionárias, patologias da prenhez e do aparelho reprodutor, a palpação retal como a ultrassonografia são técnicas não invasivas e têm importância fundamental para o manejo humanitário das gestantes (Barros and Visintin, 2001). Este manejo deve ser criterioso, uma vez gestante a fêmea deve ser separada das demais categorias animais, sendo colocadas em piquetes especiais, que ofereçam conforto e bem-estar (Pereira et al., 2010).

\section{Instalações zootécnicas}

O manejo eficiente num sistema de criação de bovinos depende diretamente de boas instalações, tendo em vista que elas representam estrutura de fundamental importância para o produtor rural organizado (Marques, 1988), bem como para o bem-estar dos animais. Dessa forma, o criador deve planejar meticulosamente o dimensionamento das estruturas que compõem cada instalação da sua propriedade, tendo em mente que seus componentes, variam, de forma geral, com a finalidade e necessidade do sistema de criação. Entre estes, o tipo de exploração (extensivo ou intensivo), área disponível na propriedade, número de animais, condições climáticas da região, topografia do terreno, entre outros componentes que facilitem ou dificultem o planejamento e a construção da infraestrutura do sistema de criação. A modernização da construção de modelos físicos dos sistemas de produção animal levaram os produtores rurais a programar nas propriedades o desenvolvimento de sistemas de criação de forma intensiva, caracterizando uma situação que é conhecida como indústria de produção animal (Paranhos da Costa, 2004). De acordo com este autor, não há dúvidas que essas condições têm proporcionado ganhos econômicos e sociais importantes, mas também têm resultado em problemas quanto ao bem-estar animal. Menciona, ainda, que o animal deve ser caracterizado pela expressão de suas necessidades e de seus desejos. Nesse ponto estaríamos na fronteira do conhecimento que trata da psicologia 
dos bovinos (Dawkins, 2017). Para este autor, vale ressaltar, nesse sentido, o conceito de ambiência que, de forma genérica, seria o espaço constituído por um meio físico, e ao mesmo tempo, por um meio psicológico, preparado para o exercício das atividades do animal que nele vive. Quando bem dimensionado e confortável o estábulo é uma construção importante numa exploração leiteira, pois possibilita um aproveitamento racional da mão de obra, além de ser imprescindível para o manejo da gestante e das fêmeas paridas. De forma semelhante, os currais são estruturas indispensáveis em qualquer tipo de criação de bovinos; portanto, devem ser bem dimensionados para evitar acidentes durante o manejo dos animais. As cercas são necessárias para delimitar os piquetes, dividir os pastos e proporcionar melhor aproveitamento das forrageiras. Em algumas situações as cercas de arame liso são mais indicadas pelo fato de causar menos riscos de lesões no corpo das fêmeas gestantes.

O tronco de contenção é uma estrutura indispensável no curral de manejo. Todas estas estruturas devem ser dimensionadas e construídas de forma que causem o mínimo de estresse e evitem acidentes durante as movimentações nos procedimentos de manejo dos animais, notadamente das gestantes, das parturientes e seus recém-nascidos.

As fêmeas gestantes devem ser alojadas em piquetes separados, para facilitar o manejo. No terço final da gestação elas devem ser transferidas para outro piquete menor, conhecido por piquetematernidade. Este piquete deve ser apropriado para oferecer o bem-estar da fêmea gestante até o parto. Portanto, tem que ser higiênico, confortável, dispor de pastagem de boa qualidade e de um abrigo para proteger as fêmeas das intempéries. Este abrigo deve possuir comedouro para suplementação alimentar, bebedouro com água potável e cochos com suplementação mineral balanceada. A característica mais importante deste piquete é que o mesmo deve ser situado em ambiente tranquilo, longe de aglomerações. No entanto, deve ser próximo da residência de um funcionário responsável pelo manejo das gestantes, para garantir assistência no momento adequado. É importante salientar também que este piquete seja situado próximo ao curral de manejo, o qual deve dispor de um tronco de contenção seguro para facilitar os cuidados sanitários da fêmea e da sua cria, bem como permitir auxílio obstétrico, no caso de uma distocia ou tratamento de distúrbios puerperais, quando necessários.
Após a fase puerperal a matriz, juntamente com sua cria, deve ser transferida do piquetematernidade para outro piquete, denominado de piquete de fêmeas paridas. Este último deve ser maior para oferecer disponibilidade de pastagem suficiente para as fêmeas e para os bezerros, até o desmame.

Sabe-se que, muitas vezes, as gestantes são tratadas com negligência ou até com maus-tratos, alojadas em piquetes inadequados, sem abrigos, desconfortável, anti-higiênico, situado em terrenos pedregosos ou íngremes, em locais úmidos, ou até mesmo alagado e, principalmente, longe da residência do responsável pelo manejo dos animais. Nestas condições, as gestantes e os recém-nascidos estão vulneráveis as infestações por ectoparasitos, aos acidentes, ataques por cães, abutres, ou dependo da região, animais silvestres. Ainda, no caso de ocorrência de parto distócico a fêmea está sujeita ao estresse, a dor e sofrimento, podendo levar a morte da parturiente e da sua cria, de forma cruel e desumana.

\section{Transporte das gestantes}

Nas condições atuais predomina o transporte rodoviário, sendo assim, este tipo de transporte é o meio mais utilizado para conduzir os animais. $\mathrm{Na}$ União Europeia as Leis sobre animais de produção são conhecidas pelas "diretivas", sendo estas não apenas recomendações, mas sim um resultado alcançado (Paixão, 2005). Os principais aspectos abordados por essas "diretivas" são aqueles que comprometem basicamente as "cinco liberdades". A "diretiva do transporte" estabelece diferentes planos de viagem, variando de acordo com a espécie animal, mas sempre que ultrapassar oito horas de viagem, deve estar incluída a previsão de água, alimento e descaso para o animal (FAWC, 2009).

No Brasil, o trânsito de animais está controlado pelo Governo Federal, sendo realizado pelo Serviço de Defesa Sanitária Animal do Ministério de Agricultura, Pecuária e Abastecimento (MAPA). No Estado de São Paulo foi estabelecido pela Lei 11.977 de 25 de agosto de 2005 (São Paulo, 2005), a qual instituiu o Código de Proteção aos Animais do Estado, na Seção III, Artigo 16, a proibição do transporte de gestantes com mais da metade do período gestacional, exceto para atendimento de urgência. Na prática cotidiana, os procedimentos de embarque/desembarque dos bovinos nos ambientes de criação caracterizam-se pelo início do processo de transporte para outros 
sistemas de criação ou para o abatedouro. Nesta etapa é onde as preocupações devem começar, pois os animais estão vulneráveis a estresse, negligências e aos maus tratos. Durante o manejo do embarque/ desembarque, na maioria das vezes os funcionários responsáveis por estes procedimentos não têm formação e conhecimento das responsabilidades e dos princípios básicos das leis de proteção animal, às quais condenam o combate aos maus tratos dos animais. Sendo assim, as fêmeas gestantes são impulsionadas por métodos não recomendados como estocadas abusivas com fragmentos de madeira, às vezes pontiagudo, chicotadas com cordas de couro ou uso de estímulos elétricos. Estes procedimentos obrigam os animais a entrarem nos veículos de transporte, de forma violenta, em decorrência dos maus tratos, causando dores e sofrimentos desnecessários. Ao conduzir as gestantes ao embarcador/desembarcador devem-se verificar as condições de integridade e a segurança do mesmo. Às vezes, estas estruturas apresentam-se de forma inadequada, com rampas escorregadias ou com inclinação muito íngreme, ou mesmo sem as grades laterais de proteção. Em algumas situações, os veículos de transporte não oferecem segurança adequada, como piso escorregadio ou com apresentação de frestas ou fendas. Estas estruturas quando inadequadas representam fatores de riscos para a ocorrência de acidentes, entre eles, ferimentos, contusões, luxações de articulações ou até mesmo fraturas dos membros.

A relação existente entre lesões traumáticas significativas associadas às condições de transporte rodoviário de bovinos tem sido motivo de estudo. No estudo realizado por Huertas et al. (2014) foi evidenciado que $68,8 \%$ dos animais transportados em caminhões apresentaram pelo menos uma lesão traumática no corpo. Sem dúvida, estes resultados fornecem subsídios para centralizar esforços políticos no sentido de promover os fatores determinantes para o bemestar animal, notadamente da fêmea gestante. Sabe-se que no transporte rodoviário do Brasil as atividades são realizadas por empresas transportadoras que prestam serviço com várias modalidades de pagamento. Geralmente em função do seguro incluído no preço, prestam bom atendimento, não acarretando maus tratos aos animais transportados, uma vez que se responsabilizam pelas perdas, acidentes e mortes durante o percurso. No entanto, percebemos que nosso País o sistema de transporte dos animais ainda deixa muito a desejar. O uso de veículos não apropriados, a superlotação animal, bem como o manejo inadequado do transporte faz parte do cenário da vida dos animais.

\section{Abate de gestante}

O sacrifício de animais destinado à alimentação humana não precisa ser um ato revestido de crueldade desnecessária. $\mathrm{O}$ abate humanitário é o ponto fundamental do bem-estar animal (Barbosa Filho and Silva, 2004). Nos países desenvolvidos há uma demanda crescente pelos abates humanitários, visando reduzir sofrimentos inúteis ao animal a ser abatido. No Brasil, de acordo com a Instrução Normativa $n^{\circ} 3$, de 17 de janeiro de 2000 (BRASIL, 2000), do Ministério da Agricultura, Pecuária e Abastecimento-MAPA, os procedimentos de abate humanitário são constituídos por um conjunto de diretrizes técnicas e científicas que garantem o bem-estar dos animais desde a recepção até a operação de sangria. De acordo com o Regulamento de Inspeção Industrial e Sanitária de Produtos de Origem Animal - RIISPOA, de 1997 (BRASIL, 1997), do MAPA foi estabelecido no Artigo 113 que, deve-se evitar, a juízo da Inspeção Federal, a matança de fêmeas em estado adiantado de gestação, com mais de dois terços do tempo normal da prenhez. No artigo 114, do mesmo regulamento, estabeleceu que fêmeas paridas ou que abortaram recentemente só pode ser abatido no prazo mínimo 10 dias após o parto ou aborto desde que não sejam portadoras de doenças infecto-contagiosas.

No Estado de São Paulo na Lei 11.977, de 25 de agosto de 2005 (São Paulo, 2005), a qual instituiu o Código de Proteção aos Animais, ficou estabelecido na Seção V, Artigo 19, que nos procedimentos de abate dos animais é obrigatório, em todos os matadouros do Estado, o emprego de métodos científicos de insensibilização aplicados antes da sangria por instrumentos de percussão mecânica, por processamento químico, choque elétrico, ou ainda, por outros métodos modernos que impeçam o abate cruel de qualquer tipo de animal destinado ao consumo. No entanto, nesta Lei não consta, em nenhum item, restrição no abate de fêmeas gestantes. A adoção de métodos para diminuir ou impedir a matança dessas fêmeas parece ser bastante complexo. Assim, vários animais são abatidos, indiscriminadamente, nas diversas fases gestacionais.

Neste sentido, fica evidente a necessidade de estudos e pesquisas em políticas públicas para que 
seja realizado um diagnóstico da situação para exercer pressão junto aos criadores, a indústria de matança e as autoridades competentes para que esse problema seja solucionado da melhor forma possível, evitando assim, mais um comprometimento ético e moral da sociedade. Partindo desta ideia, atitudes como o lançamento de um selo de criação, manejo e abate humanitário dos animais, ou organizações de protestos e boicotes podem ser no futuro próximo, a nova vertente do mercado mundial de carnes no Brasil, intensificando a ideia de alimentos ditos "éticos" que são aqueles obtidos de forma mais humanitária possível.

\section{Plantas tóxicas que causam aborto}

A falta de uma definição do que seja planta tóxica na pecuária fez com que muitas plantas fossem indevidamente incluídas nesta categoria (Tokarnia and Dobereiner, 1979, Tokarnia, 2000). Segundo estes autores planta tóxica, do ponto de vista pecuário, são aquelas que, quando ingerida pelo animal em condições naturais, causam danos a sua saúde ou mesmo a sua morte. No rebanho bovino, a intoxicação por plantas é a terceira causa de mortes no Brasil, sendo a primeira a raiva e a segunda, o botulismo (Tokarnia, 2000). Segundo estes autores há aproximadamente 70 plantas tóxicas de interesse pecuário, que já tiveram sua toxidez confirmada por experimentos.

As mortes dos animais intoxicados por plantas ocorrem mais no período da seca devido à péssima qualidade das pastagens, acarretando inúmeros prejuízos econômicos (Caldas et al., 2005). Assim, várias plantas tóxicas já foram estudadas e identificadas por diversos pesquisadores como causadoras de danos à saúde e mortalidade em bovinos, tanto nos campos como nas pastagens das diversas regiões do Brasil (Haraguchi, 2003, Tokarnia, 2000). Várias plantas são incriminadas, por criadores, de serem abortivas para os bovinos, entretanto, é necessário dados objetivos e experimentais que provem ou não estas suposições (Tokarnia (Tokarnia et al., 1960, Tokarnia and Döbereiner, 1967, Tokarnia et al., 1989). Algumas toxinas de plantas têm potencial para causar perda embrionária e fetal (Hafez and Hafez, 2004). Segundo estes autores, em muitos casos, o aborto poderá ocorrer em $100 \%$ dos animais que tiverem consumidos algumas dessas toxinas.

No Brasil, foi possível demonstrar, via experimentos em bovinos, a ação abortiva de três plantas: Tetrapterys spp, Ateleia glazioviana e barbatimão ou Stryphnodendron obovatum (Tokarnia, 2000). Segundo estes autores a Tetrapterys spp afetam o funcionamento do coração, causando intoxicação subaguda a crônica, com alterações regressivas graves e fibrose cardíaca. Mencionam, ainda, que além de possuírem esta ação, também são abortivas. Mostram ainda que a planta Ateleia glazioviana é uma árvore leguminosa conhecida popularmente como "maria-preta" ou "timbó," provocam aborto com maior frequência no final do verão e do outono, no período de escassez de alimentos. Nos animais intoxicados experimentalmente por esta planta estes autores observaram sintomas caracterizados por pêlos arrepiados, letargia, andar cambaleante, decúbito, edema do úbere e da vulva, além de aborto, retenção de placenta e endometrite. Estes autores mencionam também que os abortos ocorrem em qualquer fase da gestação em fazendas onde esta planta está presente em elevada concentração e sempre estão relacionados a períodos de escassez de alimentos. Sendo assim, os criadores deveriam colocar vacas em gestação nas pastagens onde não existe esta planta. No caso de intoxicação experimental por Stryphnodendron obovatum (Tokarnia, 2000) observou sintomas como diminuição do apetite e da atividade ruminal, sialorreia, dificuldade em se levantar, andar desequilibrado, tremores musculares, emagrecimento e finalmente aborto ou morte fetal com mumificação.

Fundamentado no exposto as fêmeas bovinas gestantes devem ser manejadas em ambientes livres de plantas tóxicas que afetem a saúde materna e fetal. Para tanto, para garantir qualidade de vida aos animais, o produtor deve estar atento quanto à presença destas plantas em sua propriedade. É importante salientar que algumas espécies de plantas tóxicas possuem princípios tóxicos que podem ser acumulados no organismo animal, podendo comprometer mais de uma gestação.

\section{Parto fisiológico ou eutócico}

O parto é definido como processo fisiológico onde o feto e os seus envoltórios são expelidos do útero pelas contrações uterinas e abdominais finalizando com o nascimento (Prestes, 2005, Pereira et al., 2010). Segundo estes autores o desenvolvimento de um parto eutócico envolve interações de fatores hormonais, neurológicos, morfológicos, fisiológicos e bioquímicos. A forma mais saudável de manejar as gestantes é mantê-las 
livres em pastos bem formados, com alimentação suplementada e exercício ao ar livre. Estas condições favorecem conforto e bem-estar, além de contribuir para o desenvolvimento de uma gestação normal. No terço final da gestação as fêmeas devem ser observadas, diariamente, para melhor avaliação de ocasionais transtornos do estado geral da parturiente e da própria gestação. O parto não é um evento abrupto, que simplesmente representa o final do período de gestação. Na realidade é um acontecimento que se desenvolve gradativamente, acompanhado de modificações fisiológicas da fêmea gestante, bem como do próprio feto (Arthur and Santos, 1979, Grunert et al., 2005, Prestes, 2005). O tempo de expulsão do feto normalmente varia de uma a quatro horas, podendo se estender para seis horas em fêmeas da primeira parição (Toniollo and Vicente, 2003, Prestes, 2005). Segundo Arthur and Santos (1979) a divisão do parto em três estágios facilita a descrição, no entanto, não existe uma demarcação clara entre estes estágios, os quais normalmente se unem para formar um processo contínuo e a extensão de cada estágio é bastante variável. Também, descreve que os eventos fisiológicos que ocorrem no primeiro estágio são: relaxamento e dilatação da cérvix; posicionamento fetal para o nascimento; início das contrações uterinas e insinuação do corioalantóide na vagina. No segundo estágio este autor menciona os seguintes eventos: continuação das contrações uterinas; insinuação do feto no canal do parto; início das contrações abdominais; insinuação do âmnio na vagina e finalmente, expulsão do feto. No terceiro estágio o referido autor descreve os seguintes eventos: perda da circulação placentária; deiscência placentária; contrações abdominais e finalmente, expulsão da placenta.

De acordo com Prestes (2005) e Cunningham (2011) o primeiro estágio do parto envolve a apresentação do feto no orifício interno da cérvix. Estes autores mencionam que, no segundo estágio a cérvix se abre, o feto passa pelo canal pélvico e a pressão abdominal é acompanhada por fechamento da epiglote e as contrações dos músculos abdominais maternos tornam-se a força principal envolvida no processo do parto. Ainda, enfatizam que o terceiro estágio é caracterizado pela expulsão das membranas fetais. Estas membranas são eliminadas entre 30 minutos a oito horas e a retenção das mesmas por mais de 12 horas deve ser considerada como patológica (Grunert et al., 2005, Prestes, 2005). Segundo
Toniollo and Vicente (2003) a expulsão da placenta leva aproximadamente de uma a seis horas, podendo chegar a 24 horas, enquanto que Arthur and Santos (1979) consideraM que as membranas fetais são normalmente expelidas dentro de 12 horas após o nascimento. De acordo com este autor a retenção além das 12 horas é frequentemente seguida de um período adicional de retenção que dura de 3 a 10 dias, a não ser que sejam removidas manualmente.

Deve-se reconhecer que as pessoas que lidam com os animais, cotidianamente, têm a oportunidade de aprender muito sobre o comportamento animal (Paranhos da Costa, 2004). Ainda, enfatiza que este conhecimento (empírico) permite a muitos identificar as necessidades dos animais e antecipar suas reações frente a determinadas situações, definindo, assim, uma forma biologicamente orientada de relacionamento com os animais. Dessa forma, torna-se necessário que os responsáveis pelo manejo das fêmeas parturientes estejam familiarizados com as fases do parto, para reconhecer, imediatamente, se o processo deixou de ser fisiológico e passou a ser patológico. A dificuldade do parto pode ser de origem materna ou fetal quando resulta de anormalidades na apresentação ou posição do feto e de irregularidades na postura da cabeça ou dos membros (Hafez and Hafez, 2004, Arthur and Santos, 1979). Seja qual for à dificuldade o parto distócico deve ser considerada uma emergência e caso não haja assistência médico-veterinária a parturiente poderá sofrer bastante ou até causar a morte da mesma, juntamente com sua cria, de forma cruel e desumana. As novilhas são mais susceptíveis a este tipo de problema, portanto, os cuidados com as mesmas têm que ser redobrados (Arthur and Santos, 1979).

\section{Partos duplos ou triplos decorrentes de biotecnologias reprodutivas}

Considera-se de grande importância as contribuições das biotecnologias reprodutivas para o avanço técnico-científico e econômico no mundo. No entanto, existem inconveniências e riscos dessas biotecnologias reprodutivas, entre elas a ruptura de barreiras éticas quanto à manipulação da vida (Figueiredo and Molento, 2008). De acordo com estes autores as biotécnicas reprodutivas como fertilização in vitro (FIV), clonagem, transgenia, entre outras biotecnologias devem-se tomar as precauções e cuidados durante 
as manipulações com objetivo que as crias resultantes nasçam saudáveis, evitando, portanto, o sofrimento animal decorrente de múltiplas patologias geradas muitas vezes por imperfeições da técnica empregada (Colli, 2011).

Os partos gemelares ocorrem em cerca de 3\% de todos os casos (Gonçalves et al., 2008). Segundo estes autores os trigêmeos são menos comuns, mas já foi registrado na literatura o nascimento de 11 bezerros. Menciona ainda que, a vaca não está preparada para lidar com nascimentos múltiplos e na ocorrência deste pode apresentar diversos problemas na gestação e no parto, entre eles a distocia por apresentação simultânea de dois fetos, incidência de inércia uterina e de retenção de placenta. De acordo com Arthur and Santos (1979) a gestação de gêmeos geralmente culmina em distocias, ambos os fetos se apresentam simultaneamente e tornam-se impactados na pélvis materna. Esta condição se agrava quando o parto ocorre em fêmeas de primeira cria, as quais tendem a demorar mais que as pluríparas (Toniollo and Vicente, 2003). Neste caso, pode resultar na incapacidade da parição normal, necessitando de auxílio obstétrico (Silva Filho et al., 2014). No estudo de Patterson et al. (1987) foi demonstrado 59\% de mortalidade de bezerros no parto em fêmeas primíparas.

A biotecnologia reprodutiva tem avançado nos últimos anos e conseguido resultados relevantes. Sendo assim, é possível induzir a produção de gêmeos, utilizando-se dos métodos da reprodução assistida e com o emprego de novas biotécnicas na reprodução. Assim, é possível aumentar a taxa de prenhez e a produção de gêmeos pela seleção de doadoras, indução da ovulação, transferência de um segundo embrião em receptora previamente inseminada, transferência de dois embriões numa mesma receptora, ou transferência de dois embriões heme-embriões, obtidos pela técnica de bipartição (Brem, 1990, Gray et al., 1991, Reichenbach et al., 1992, Knight et al., 2001, Bergamaschi et al., 2002, Gonçalves et al., 2008). Nota-se o esforço e o progresso alcançado pela comunidade científica e pela iniciativa privada na consolidação e domínio da biotecnologia onde estão disponíveis técnicas eficazes para a multiplicação animal com produtividade desejada, bem como sua utilização no manejo mais adequado (Prestes, 2005). No entanto, a ética e o controle de produtos gerados a partir de técnicas que não estão completamente dominadas devem estar presentes na utilização das novas biotecnologias, para que as gerações futuras não sofram graves prejuízos originados por sua utilização inadequada. Neste contexto, faz-se necessário o uso consciente frente aos avanços das biotecnologias reprodutivas buscando atenção quanto às limitações e implicações éticas, legais e morais.

\section{Parto patológico ou distócico}

O parto distócico é caracterizado pela dificuldade ou impedimento do nascimento do feto devido a problemas de origem materna, fetal ou materno-fetal. $\mathrm{Na}$ obstetrícia bovina o momento exato para intervir na assistência médica e preservar a vida do feto ainda é indeterminado sendo que a intervenção obstétrica precoce pode causar danos ao feto e via fetal de nascimento devido à dilatação insuficiente. No entanto, o retardo no auxílio obstétrico pode comprometer a vida fetal (Neves et al., 2010).

Mundialmente a incidência de distocias em bovinos leiteiros é menor que 5\%, no entanto, a taxa de partos assistidos varia de 10 a 50\% (Mee, 2008). O estudo realizado por Silva Filho et al (2014) demonstrou $47,7 \%$ de distocia fetal, $44,5 \%$ de distocia materna e $7,8 \%$ de distocia maternofetal, enquanto que Borges et al (2006) mostrou $65,7 \%$ de distocia fetal e $25,5 \%$ de distocia materna. Levando-se em consideração a importância do bem-estar da parturiente a distocia deve ser evitada, a medida do possível. Para Borges et al. (2007) esta condição apresenta efeitos adversos e compromete o bem-estar da parturiente, caso a mesma não seja assistida por um veterinário obstetra, onde se espera que a dor e sofrimento sejam minimizados. Enfatiza, ainda, que infelizmente vários casos de distocias em bovinos são mal conduzidos por proprietários ou seus auxiliares os quais usam força excessiva de forma inadvertida. Menciona também que tanto a vaca quanto o bezerro podem estar sujeitos a lesões graves, ocasionando lesões vaginais graves. Além disso, o autor enfatiza que cuidados especiais podem ser requeridos para a fêmea que apresentou distocia, principalmente se esta foi complicada por lesões teciduais e infecções. Observou-se que $86,5 \%$ de parturientes atendidas na Clínica de Bovinos de Garanhuns da Universidade Federal Rural de Pernambuco houve manipulação prévia por proprietários e leigos antes do atendimento obstétrico (Silva Filho et al., 2014). Segundo estes autores os dados mostram que estas intervenções colocam em risco a vida do feto e da parturiente e em função disso observou- 
se que $60 \%$ dos fetos e $15 \%$ das vacas vinham a óbito após o parto. Mostraram ainda que nas parturientes não manipuladas o índice de mortalidade caiu para $31 \%$ dos fetos e $8 \%$ das vacas. Neste sentido, é imprescindível que a gestante seja mantida em pique-maternidade. Este piquete deve oferecer conforto e bem-estar aos animais devendo ser ainda localizado próximo da residência do campeiro para que haja um acompanhamento do parto, à medida do possível. Este acompanhamento é mais comum nos bovinos leiteiros, no entanto, nada impede que as instalações dos bovinos de corte sejam dimensionadas para que haja condições da assistência ao parto. Neste caso, vários pequenos piquetes podem ser construídos e intercalados a um corredor que se comunica com o curral de manejo. Este curral deve possuir um tronco de contenção para imobilização de uma fêmea afetada por uma distocia e ser assistida por médico veterinário.

\section{Patologias da prenhez}

Várias patologias podem comprometer a saúde da fêmea afetando a gestação e o feto. Entre elas o prolapso da vagina é uma afecção importante e comum que requer manejo cuidadoso, podendo ocorrer tanto durante a gestação quanto após o parto (Grunert et al., 2005, Borges et al., 2007). Para Arthur Arthur and Santos (1979) o prolapso vaginal é uma patologia observada nos ruminantes em prenhez adiantada, ou seja, nos últimos dois meses, podendo ocorrer após o parto. De acordo com Toniollo and Vicente (2003) esta patologia pode apresentar-se de forma parcial, quando apenas uma parte da parede vaginal é exteriorizada, ou de forma total, quando a vagina projeta-se totalmente para fora da rima vulvar, expondo a cérvix e o tampão mucoso, quando a fêmea está gestante, constituindo o prolapso vaginal completo ou cervicovaginal. Neste caso, o órgão exposto fica vulnerável a diversas lesões de várias intensidades, como processos inflamatórios, irritação, edema, úlcera, e necrose, além de infecções (Grunert et al., 2005, Borges et al., 2007). Estes autores descrevem sintomas os quais denunciam dor e sofrimento nas diversas intensidades, entre os principais temos: retenção urinária devido à compressão da uretra, tenesmo, inquietude, esforços violentos expulsivos, anorexia e queda brusca da condição física.

Do ponto de vista zootécnico animais com tendência a prolapso não devem ser utilizados para reprodução, tendo em vista a comprovada predisposição hereditária desta patologia (Grunert et al., 2005). O exemplo do prolapso de vagina, várias outras patologias comprometem o bemestar da fêmea bovina e muitas delas causam sofrimento intenso, podendo levar a morte de forma cruel e desumana caso não haja interferência humana.

A transferência de embriões, fecundação in vitro, clonagem e transgenia são biotecnologias reprodutivas que exigem controle mais acurado na gestação e no parto pelo fato de produzir indivíduos com crescimentos exacerbados ou de menor vitalidade em decorrência de disfunções placentárias (Prestes, 2005). Este autor enfatiza a necessidade de aprimoramento na área, visando o bem-estar dos recém-nascidos e das parturientes. Portanto, cabe ao homem evitar as negligências e os maus-tratos e agir de forma ética quanto ao tratamento dos animais, notadamente na gestação onde os cuidados e a assistência devem ser intensificados. A bovinocultura não deve ser vista apenas como uma atividade única $\mathrm{e}$ exclusivamente econômica, ela tem algo mais, a vida dos animais, que deve ser digna e respeitada.

\section{Considerações finais}

No Brasil existe um grande desafio a ser superado para a definição de boas práticas de criação que possam garantir qualidade de vida dos animais de produção. Neste sentido, há necessidade que as Comissões de Ética e as Sociedades Protetoras de Animais trabalhem em parceria com as Universidades e Instituições de Pesquisas na conscientização para elaboração de Leis e Projetos de Políticas Públicas visando o bem-estar dos animais. Observa-se que no cotidiano dos ambientes de criação os cuidados com as parturientes deixam muito a desejar. Nos ambientes de criação, as atividades como auxílio obstétrico, cuidados com a parturiente e com os recém-nascidos têm sido conduzidas com negligência, imperícia ou imprudência.

O exemplo da Comunidade Europeia mostra que é possível desenvolver novas práticas nos sistemas de criação que assegurem bons índices de produtividade e alta qualidade do produto, sem comprometer o bem-estar dos animais. Como pode ser visto, existem muitas barreiras humanas, culturais, éticas e morais a serem vencidas. No caso específico dos bovinos há necessidade de entendimento de todas as etapas da cadeia de produção de carne e leite. Entre elas, destaca-se a 
saúde, reprodução, bem-estar, comportamento, alimentação, transporte, procedimentos de abate, entre outros.

\section{Referências Bibliográficas}

Arthur, G. H. \& Santos, O. R. F. 1979. Reprodução e obstetrícia em veterinária. Guanabara Koogan, Rio de Janeiro, Brasil.

Barbosa Filho, J. A. D. \& Silva, I. J. O. 2004. Abate humanitário: ponto fundamental do bem-estar animal. Revista Nacional da Carne, 328, 36-44.

Barros, B. J. P. \& Visintin, J. A. 2001. Controle ultra-sonográfico de gestações, de mortalidades embrionárias e fetais e do sexo de fetos bovinos zebuínos. Brazilian Journal of Veterinary Research and Animal Science, 38, 74-79.

Bennett, R. 1998. Measuring public support for animal welfare legislation: A case study of cage egg production. Animal Welfare, 7, 1-10.

Bergamaschi, M. A. C. M., Vicente, W. R. R., Barbosa, R. T., Marques, J. A. \& Freitas, A. R. 2002. Sincronização da ovulação em fêmeas Nelore, com associação de progestágenos, estrógenos e gonadotrofina sérica de égua prenhe. ARS Veterinaria, 18, 267-272.

Borges, M. C. B., Costa, J. N., Ferreria, M. M., Menezes, R. V. \& Chalhoub, M. 2007. Caracterização das distocias atendidas no período de 1985 a 2003 na Clínica de Bovinos da Escola de Medicina Veterinária da Universidade Federal da Bahia. Revista Brasileira de Saúde e Produção Animal, 7, 8793.

BRASIL. Ministério da Agricultura, Pecuária e Abastecimento. Departamento de Inspeção Sanitária de Produtos de Origem Animal. Regulamento da Inspeção Industrial e Sanitária de Produtos de Origem Animal. Brasília: 1997.

BRASIL. Ministério da Agricultura, Pecuária e Abastecimento. Secretaria da defesa Agropecuária. Instrução Normativa no ${ }^{\circ}$, de 17 de janeiro de 2000. Aprova o Regulamento Técnico de Métodos de Insensibilização para o abate Humanitário de Animais de Açougue. Disponível em: http: www.agricultura.gov.br. Acesso em 23 de outubro de 2006.
Brem, G. 1990. Micromanipulación en embriones bovinos y sus posibles aplicaciones en producción animal. Argentina.

Caldas, S. A., Gabriel, A. M. A., Amorim, A. \& Conceição, J. H. S. 2005. Intoxicação de bovinos por plantas no médio Paraíba, RJ. Revista Brasileira de Medicina Veterinária, 27, 27-30.

Colli, W. 2011. Organismos transgênicos no Brasil: regular ou desregular? Revista USP, 148-173.

Cunningham, J. 2011. Tratado de fisiologia veterinária. Guanabara Koogan, Rio de Janeiro.

Dawkins, M. S. 2017. Animal welfare and efficient farming: is conflict inevitable? Animal Production Science, 57, 201-208.

FAWC. 2009. Farm animal welfare in Great Britain: Past, present and future. Farm Animal Welfare Council, England.

Figueiredo, J. R. \& Molento, C. F. M. 2008. Bioética e bem-estar animal aplicados as biotécnicas reprodutivas. In: Goçalves, P. H. D., Figueiredo, J. R. \& Freitas, V. J. F. (eds.) Biotécnicas aplicadas a reprodução animal. Editora Roca, São Paulo.

Glass, C. A., Hutchinson, W. G. \& Beattie, V. E. 2005. Measuring the value to the public of pig welfare improvements: a contingent valuation approach. Animal Welfare, 14, 61-69.

Goçalves, P. H. D., Figueiredo, J. R. \& Freitas, V. J. F. 2008. Bioética e bem-estar animal aplicados as biotécnicas reprodutivas. Editora Roca, São Paulo.

Gonçalves, P. B. D., Figueiredo, J. R. \& Figueiredo Freitas, V. J. 2008. Biotécnicas aplicadas à reprodução animal. Editora Roca.

Gray, K. R., Bondioli, K. R. \& Betts, C. L. 1991. The commercial application of embryo splitting in beef cattle. Theriogenology, 35, 3744.

Grunert, E., Birgel, E. H. \& Vale, W. G. 2005. Patologia e clínica da reprodução dos animais mamíferos domésticos: ginecologia. Varela.

Hafez, B. \& Hafez, E. 2004. Reprodução Animal. Manole: São Paulo, Brasil.

Haraguchi, M. 2003. Plantas tóxicas de interesse na pecuária. Biológico, São Paulo. 
Hellebrekers, L. J. 2002. Dor em animais: uma abordagem com orientação prática para um controle eficaz da dor em animais. Manole, Barueri, São Paulo.

Huertas, S. M., Gallo, C. \& Galindo, F. 2014. Drivers of animal welfare policy in the Americas. Revue Scientifique et Technique, 33, 67-76.

Knight, T. W., Lambert, M. G., Devantier, B. P. \& Betteridge, K. 2001. Calf survival from embryo transfer-induced twinning in dairybeef cows and the effects of synchronised calving. Animal Reproduction Science, 68, 112.

Marques, D. C. 1988. Criação de bovinos. Nobel, Belo Horizonte, Minas Gerais.

Mee, J. F. 2008. Prevalence and risk factors for dystocia in dairy cattle: A review. The Veterinary Journal, 176, 93-101.

Molento, C. F. M. 2005. Bem-estar e produção animal: Aspectos econômicos - Revisão. Archives of Veterinary Science, 10, 1-11.

Neves, J. P., Miranda, K. L. \& Tortorella, R. D. 2010. Progresso científico em reprodução na primeira década do século XXI. Revista Brasileira de Zootecnia, 39, 414-421.

Paixão, R. L. 2005. É possível garantir bem-estar aos animais de produção. Revista Conselho Federal de Medicina Veterinária, 11, 66-73.

Paranhos da Costa, M. J. R. 2004. Comportamento e bem-estar de bovinos e suas relações com a produção de qualidade. Anais dos Simpósios da 4la Reunião da Sociedade Brasileira de Zootecnia. Campo Grande, Mato Grosso do Sul.

Patterson, D. J., Bellows, R. A., Burfening, P. J. \& Carr, J. B. 1987. Occurrence of neonatal and postnatal mortality in range beef cattle. I. Calf loss incidence from birth to weaning, backward and breech presentations and effects of calf loss on subsequent pregnancy rate of dams. Theriogenology, 28, 557-571.

Pereira, E. S., Pimentel, P. G., Queiroz, A. C. \& Mizubuti, I. Y. 2010. Novilhas leiteiras. Graphiti Gráfica e Editora Ltda, Fortaleza, Ceará.

Pierson, R. A. 1989. Applications of diagnostic ultrasonography in embryo transfer programs. Embryo Transfer, 4, 1-4.
Prestes, N. C. 2005. Produção in vitro de embriões bovinos-problemas e desafios-Visão obstétrica. Acta Scientiae Veterinariae, 33, 119-124.

Reichenbach, H. D., Liebrich, J., Berg, U. \& Brem, G. 1992. Pregnancy rates and births after unilateral or bilateral transfer of bovine embryos produced in vitro. Journal of Reproduction and Fertility, 95, 363-370.

Silva Filho, A. P., Azevedo, C. N., Carneiro, G. F., Souto, R. J. C., Mendonça, C. L. \& Afonso, J. A. B. 2014. Ocorrência e análise de fatores relacionados à distocias em vacas no Agreste Meridional de Pernambuco. Revista Brasileira de Medicina Veterinária, 36, 317-321.

Tokarnia, C. H. \& Döbereiner, J. 1967. Intoxicação experimental pela fava da "faveira"(Dimorphandra mollis Benth.) em bovinos. Pesquisa Agropecuária Brasileira, 2, 367-373.

Tokarnia, C. H., Döbereiner, J. \& Canella, C. F. C. 1960. Estudo experimental sobre a toxidez do "canudo"(Ipomoea fistulosa Mart.) em ruminantes. Arquivo do Instituto Biológico de São Paulo, 3, 59-71.

Tokarnia, C. H. \& Dobereiner, J. S. 1979. Plantas tóxicas da Amazonia a bovinos e outros herbívoros. Instituto de Pesquisas da Amazônia,, Manaus, Amazonas.

Tokarnia, C. H., Peixoto, P. V., Dobereiner, J., Consorte, L. B. \& Gava, A. 1989. Tetrapterys spp.(Malpighiaceae), a causa de mortandades em bovinos caracterizadas por alteraçöes cardíacas. Pesquisa Veterinária Brasileira, 9, 23-44.

Tokarnia, C. H. J. V. P. 2000. Plantas tóxicas do Brasil. Helianthus, Rio de Janeiro, Brasil.

Toniollo, G. H. \& Vicente, W. R. R. 2003. Manual de obstetrícia veterinária. Varela, São Paulo.

Article History:

Received 13 June 2017

Accepted 28 July 2017

Available on line 15 August 2017

License information: This is an open-access article distributed under the terms of the Creative Commons Attribution License 4.0, which permits unrestricted use, distribution, and reproduction in any medium, provided the original work is properly cited. 